\title{
Clinical Studies on the Efficacy and Safety of Padma 28, a Complex Herbal Formulation from Tibetan Medicine: An Overview
}

\author{
Cecile Vennos $^{a} \quad$ Jörg Melzer ${ }^{b}$ Reinhard Saller ${ }^{b}$ \\ a Scientific Medical Division, Padma Inc., Hinwil, \\ ${ }^{\mathrm{b}}$ Institute for Complementary Medicine, University Hospital Zurich, Switzerland
}

\section{Keywords}

Padma 28 - Phytotherapy - Tibetan Medicine .

Clinical studies

\section{Summary}

Background: Padma 28 is an herbal formula from Tibetan Medicine, which since 35 years has been registered in Switzerland as a drug for the symptoms of circulatory disorders. Over this time, a large body of scientific literature has accumulated. The aim of this article was to give an overview of the clinical studies. Methods: A systematic literature search was done in PubMed, EMBASE, and the Cochrane Central Register of Controlled Trials (CCRCT). The clinical trials found were assessed regarding fields of application, efficacy, and safety, as well as methodological quality and level of evidence. Results: 29 trials ( 1 meta-analysis, 21 controlled trials, 7 open trials) and 3 retrospective case studies were found. They deal with different indications and include a total of 1,704 verum (of these, 697 children), 333 placebo, and 394 untreated or healthy patients. Dropouts and withdrawals were 2.5 and 3.5 times higher in the placebo than in the verum group, respectively. The highest level of evidence for the use of Padma 28 was found in the indication of intermittent claudication (11 trials). Indications of efficacy were also found in other vascular (6 trials) and different inflammatory diseases (12 trials). Conclusions: The results suggest a favorable safety profile for Padma 28 , also in the children examined $141 \%$ of the study population). Furthermore, the results show a broad field of applications. According to clinical evidence, Padma 28 has shown to be a safe and effective symptomatic treatment option for atherosclerosis-related diseases such as intermittent claudication. It also seems to have a potential for application in certain chronic inflammatory diseases such as recurrent respiratory tract infections, viral hepatitis, and multiple sclerosis. However, further randomized controlled trials (RCT) are needed to confirm these findings.

Note: In Switzerland, Padma 28 (Swissmedic No. 58436) is also available under the names Padmed Circosan (Swissmedic No. 60131) and Arteria-vita (Swissmedic No. 62863).

\section{Schlüsselwörter \\ Padma 28 - Phytotherapie - Tibetische Medizin . \\ Klinische Studien}

\section{Zusammenfassung}

Hintergrund: Padma 28 ist eine Pflanzenformel aus der Tibetischen Medizin. Sie ist in der Schweiz seit 35 Jahren als Arzneimittel bei Symptomen von Durchblutungsstörungen registriert. Über diesen Zeitraum hat sich eine große Menge an wissenschaftlicher Literatur angesammelt. Ziel dieses Artikels war es, einen Überblick über die klinischen Studien zu geben. Methoden: Eine systematische Literatursuche wurde in PubMed, EMBASE und im Cochrane Central Register of Controlled Trials (CCRCT) durchgeführt. Die gefundenen klinischen Studien wurden bezüglich Anwendungsbereich, Wirksamkeit und Sicherheit beurteilt sowie auch bezüglich methodischer Qualität und Evidenzlevel. Ergebnisse: 29 klinische Arbeiten (1 Meta-Analyse, 21 kontrollierte und 7 offene Studien) sowie 3 retrospektive Fallstudien wurden gefunden. Diese beinhalten verschiedene Indikationen und umfassen insgesamt 1704 Verum- (davon 697 Kinder), 333 Placebo- und 394 unbehandelte oder gesunde Kontrollpatienten. Dropouts und Studienabbrüche waren 2,5- bzw. 3,5-mal häufiger in der Placeboals in der Verumgruppe. Der höchste Evidenzlevel für die Anwendung von Padma 28 zeigte sich bei der Indikation Claudicatio intermittens (11 Studien). Hinweise auf Wirksamkeit wurden auch bei anderen vaskulären ( 6 Studien) und verschiedenen entzündlichen Krankheiten (12 Studien) gefunden. Schlussfolgerungen: Die Resultate weisen auf ein günstiges Sicherheitsprofil von Padma 28, auch bei den untersuchten Kindern ( $41 \%$ der Studienpopulation), und vielfältige Anwendungsmöglichkeiten hin. Aufgrund der klinischen Evidenz erweist sich Padma 28 als sichere und wirksame symptomatische Behandlungsoption bei atherosklerosebedingten Krankheiten wie z.B. Claudicatio intermittens. Ein gewisses Anwendungspotenzial scheint bei bestimmten chronisch-entzündlichen Erkrankungen wie z.B. rezidivierende Atemwegsinfekte, Virushepatitis oder Multiple Sklerose zu bestehen. Allerdings müssen diese Ergebnisse in randomisierten kontrollierten Studien (RCT) bestätigt werden.

\section{KARGER \\ Fax +497614520714 \\ Information@Karger.com}

www.karger.com (c) 2013 S. Karger GmbH, Freiburg

1661-4119/13/0208-0025\$38.00/0

Accessible online at:

www.karger.com/fok
Prof. Dr. med. Reinhard Saller

Institut für Naturheilkunde

Universitätsspital Zürich

Rämistrasse 100, Postfach 131, 8091 Zürich, Switzerland

reinhard.saller@usz.ch 


\section{Introduction}

Padma ${ }^{\circledR} 28$ is a complex herbal preparation containing 20 herbal substances, calcium sulfate, and natural camphor. It is based on the Tibetan Medicine and has been registered as a drug in Switzerland since 1977 (Swissmedic No. 58436) for symptoms of circulatory disorders. The formula has been the object of scientific research for decades and it is a well-documented complex multi-compound herbal drug. Padma 28 acts according to a multi-target mechanism and has shown anti-inflammatory, antioxidant and some antimicrobial effects, as well as anti-coagulatory and anti-proliferative properties [1]. Such herbal combination drugs are not only the sum of their components but they build a genuine, complex active compound in which the single chemical substances are present in minute dosages and simultaneously act on different biochemical pathways to achieve their clinical effect [2]. The network character of the herbal preparation leads to a potentially broader spectrum of indications than is known for most synthetic monosubstance drugs. The aim of the present review is to give an overview of the clinical trials on Padma 28 in any investigated indication and to discuss efficacy and safety aspects of the preparation.

\section{Material and Methods}

\section{Literature Search}

Clinical studies on Padma 28 published in German or English were systematically searched in the PubMed, EMBASE and Cochrane Central Register of Controlled Trials (CCRCT) databases, from their beginning up to February 2007. Further data sources were the collected literature of Padma Inc. and the list of references of the studies found. If a trial was published twice, this study was included only once.

\section{Methodical Quality and Level of Evidence}

The studies were assessed regarding methodical quality and level of evidence according to Jadad et al. [3] and the National Health and Medical Research Council (NHMRC) of the Commonwealth of Australia [4], respectively.

\section{Results}

From a time span of almost 30 years, 30 publications were found: 1 meta-analysis, 26 publications reporting on 28 clinical trials, and 3 retrospective case studies (RC). They include a total of 1,704 verum patients (per protocol) as well as 333 placebo and 394 untreated or healthy controls (fig. 1). The intention-to-treat (ITT) numbers were 1726 in the verum and 355 in the placebo group. The rate of dropouts and withdrawals were $2.3 \%$ in the verum and $5.8 \%$ in the placebo group; the rates of adverse events (AE) were $2.2 \%$ and $7.8 \%$, respectively. The studies were conducted in patients with intermittent claudication, other vascular diseases, lipid metabolism disturbances, and with inflammatory/immunological conditions.

\section{Padma 28 in Intermittent Claudication}

On intermittent claudication, 11 studies were found (table 1). They included 266 verum and 204 placebo patients (ITT 266 and 225). 1 meta-analysis, 8 randomized controlled trials (RCT) and 1 controlled trial (CT) were in peripheral artery disease (PAD) Fontaine stage II [5-14] (table 1). Of the studies found, the trials in this group were of the highest methodical quality and, due to a meta-analysis [5], also had the highest level of evidence according to the NHMRC [4]. For the metaanalysis, the raw data of 5 CTs [6-10] were re-analyzed accordingly to ITT for pooling, and a significant increase of the maximum walking distance (MWD) was found. An increase of $>100 \mathrm{~m}$ was rated as clinically significant and was found in $18.2 \%$ of the verum and $2.1 \%$ of the placebo patients $(\mathrm{p}<0.001$; number needed to treat: 6.2 ). The meta-analysis additionally showed small but statistically significant effects in decreasing blood glucose, blood lipids, and systolic as well as diastolic blood pressure [5]. 3 trials in intermittent claudication were not included in the meta-analysis, 2 because of other clinical endpoints and 1 because of another indication (PAD Fontaine stages III and IV). 1 RCT analyzed the ankle/brachial index $(\mathrm{ABI})$ and the exercise-induced blood pressure drop in patients with intermittent claudication [11]. While the ABI did not significantly change, the pressure drop after treadmill
Fig. 1. Number of patients treated with Padma 28 or placebo and of controls (untreated or healthy) in different indications (only clinical trials).

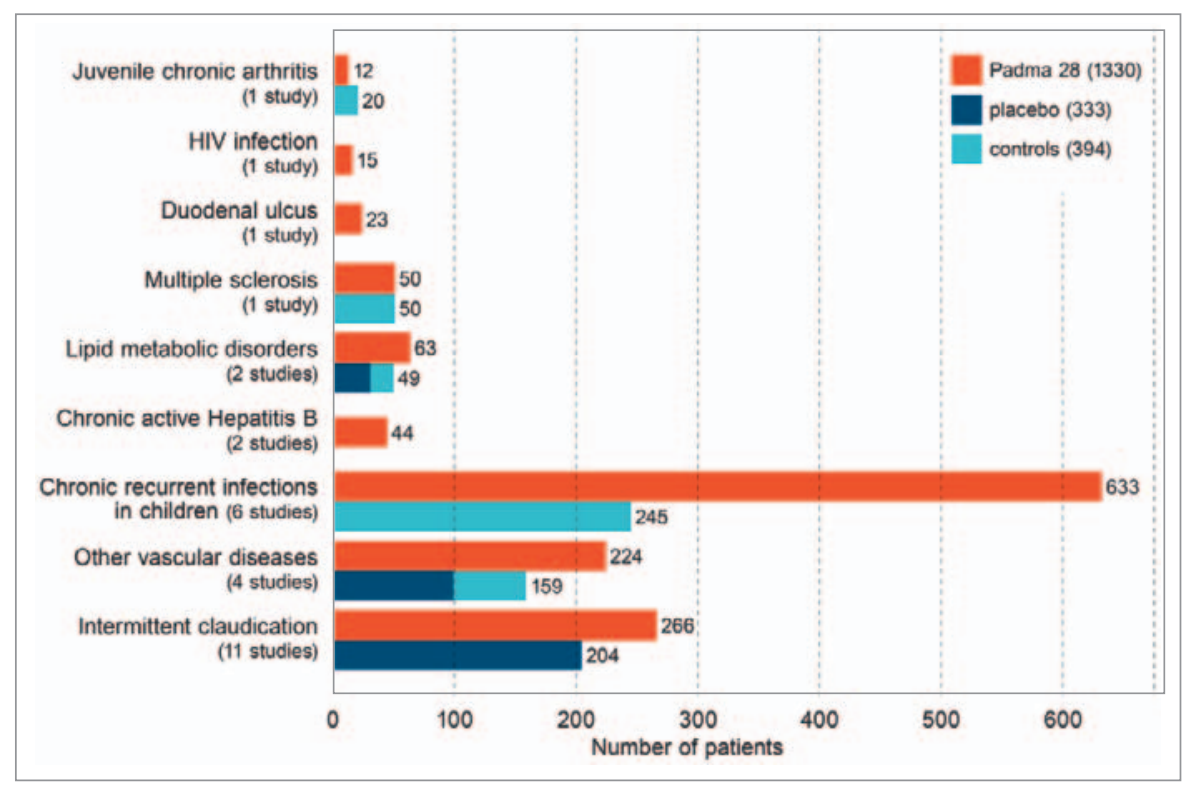




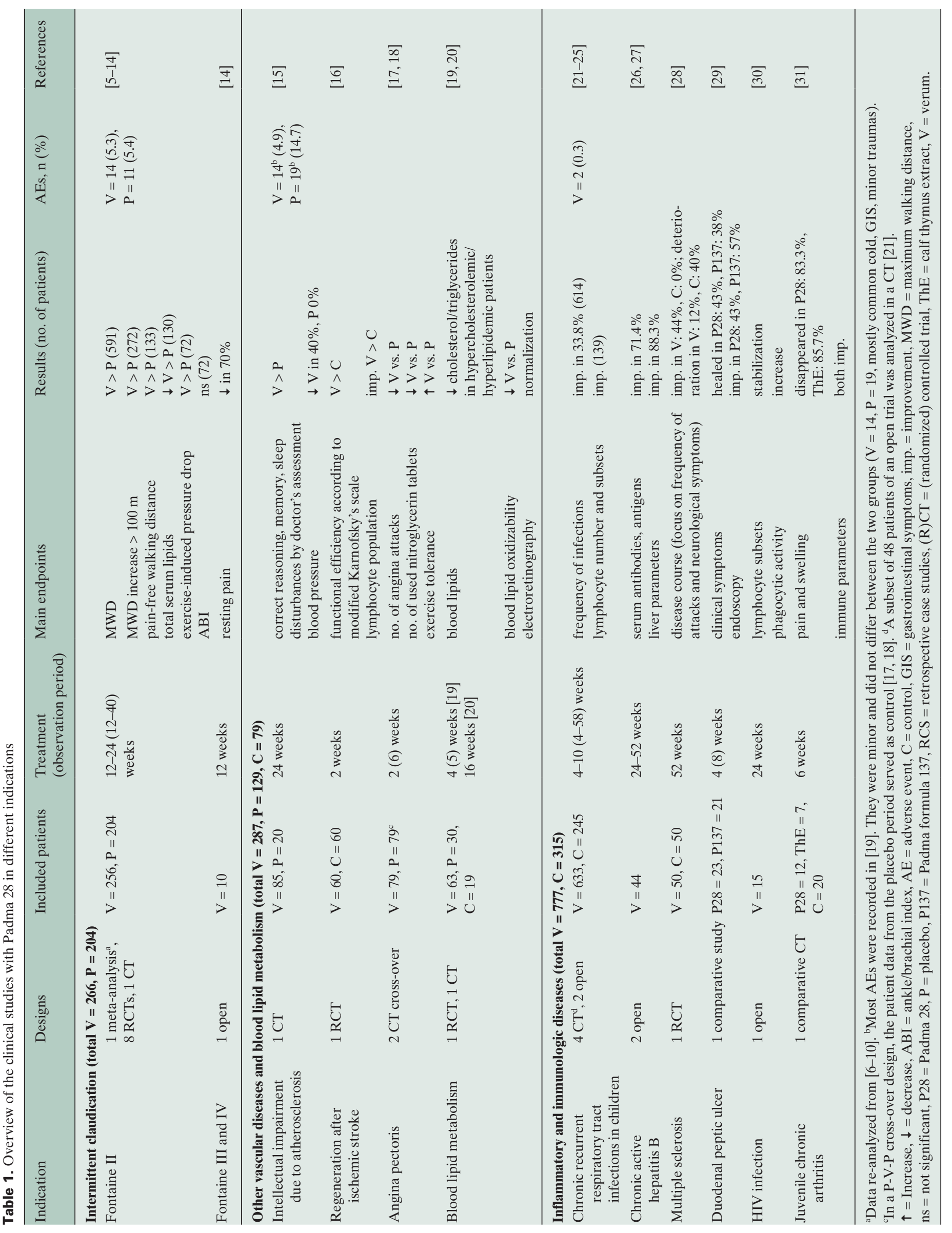


walking exercise was significantly decreased with Padma 28 $(\mathrm{p}=0.031)$ and the ischemic window decreased $(\mathrm{p}=0.040)$. Another RCT in intermittent claudication patients, analyzing blood coagulation parameters and the oxidative burst response of monocytes, found significantly improved fibrinolytic activity and a decreased oxidative burst response (both $\mathrm{p}<0.05)$ [13]. The oldest published study was in patients with PAD Fontaine stages III and IV and found an improvement of cramps and paresthesias and pain-free walking distance as well as a reduction of resting pain under verum [14].

Padma 28 in Other Vascular Diseases and Lipid Metabolism In other atherosclerotic diseases than intermittent claudication, 4 studies were found. They included 224 verum, 99 placebo, and 60 untreated control patients (table 1). 1 CT in patients with impaired intellectual function due to atherosclerosis found an improvement in correct reasoning, memory and sleep disturbances as well as lowering of increased blood pressure in patients with Padma $28(\mathrm{n}=85)$ compared to placebo $(\mathrm{n}=20)$ [15]. 1 RCT in patients after ischemic brain stroke found an improvement in functional efficiency according to Karnofsky scale and immune parameters such as lymphocyte populations in patients with the preparation compared to standard treatment $(\mathrm{n}=60$ each) [16]. 2 placebo-controlled, cross-over CT in patients with angina pectoris analyzed the frequency of attacks, the use of glyceryl trinitrate tablets, and the exercise tolerance $(n=79)$ and found improvements of these parameters $[17,18]$.

A further 2 studies measured changes in blood lipid metabolism. They included 63 verum and 30 placebo patients (ITT 64 and 31) as well as 19 healthy controls. 1 RCT showed a reduction of the oxidizability of blood lipids by the preparation [19] and 1 CT found a significant reduction of triglycerides or cholesterol in patients with hypertriglyceridemia or hypercholesterolemia, respectively [20]. Additionally, the treatment normalized the oscillatory potentials, a marker for increased blood lipids and early atherosclerosis.

\section{Padma 28 in Infectious and Immunological Diseases}

In various inflammatory conditions of infectious or autoimmune origin, 15 studies were found. They included 1,004 verum patients (ITT 1011), 265 untreated and 50 healthy controls. 6 of these (4 CT and 2 open studies) were conducted in recurrent respiratory tract infections in children [21-25], which included by far the largest patient groups with 633 verum patients (ITT 636), 205 untreated, and 40 healthy controls (table 1). They found a decrease in the frequency of infections as well as an improvement of immunologic parameters such as lymphocyte numbers and subsets as well as phagocytic activity by the Padma 28 treatment compared to controls. 2 open trials in 44 patients with viral hepatitis B showed improved serological status and biochemical parameters [26, 27]. 1 RCT in patients with progressive multiple sclerosis found an improvement in $44 \%$ and a deterioration in $12 \%$ of the verum group compared to zero improvement but $40 \%$ deterioration in patients with symptomatic treatment (analgesics, spasmolytics) alone over 1 year of treatment [28]. 1 comparative study (comparison of treatment with another multi-herbal formula) in 23 patients with duodenal peptic ulcer showed complete remission in $43.5 \%$ of the patients and improvement in another $43.5 \%$ treated with the phytotherapeutic, as assessed by endoscopy [29]. In 1 open pilot study, a stabilization of lymphocyte subsets (total $\mathrm{T}$ cells, helper-inducer cells, suppressor T cells, Leu 2+, 7+ T cells, NK cells) and an increase in phagocytic activity was found in 15 human immunodeficiency virus (HIV)-positive verum-treated patients [30]. 1 trial including 12 patients with juvenile chronic arthritis showed a decrease of pain and swelling and of the number of affected joints in $83.3 \%$ of the treated patients, as well as an improvement of immune parameters (decrease of the erythrocyte sedimentation rate, increase of the CD4/CD8 ratio) [31].

\section{Retrospective Case Studies}

Besides the clinical trials, the literature search produced 3 RC. 1 of them collected data on the indications in which Padma 28 was used by Swiss physicians, as well as on the efficacy and tolerability as assessed by physicians and patients [32]. 15 physicians reported on 147 individual patients with 226 symptoms, of which $75 \%$ were due to cardiovascular disorders like peripheral arterial disease (PAD), angina pectoris, and cerebral circulatory disorders. The efficacy was rated as 'good' in $76 \%$ and $78 \%$ of the cases by the physicians and the patients, respectively. In 1 RCS in 49 patients (ITT 53) with dental pulpitis without a clear indication for an immediate root canal treatment, $73 \%$ of the patients were free of pain within 2 months of the treatment and a root canal was still necessary in $18 \%$ [33]. $1 \mathrm{RCS}$ was performed in the indication of chronic active hepatitis $\mathrm{B}$, for which there are also data from 2 open trials. In $90 \%$ of the 126 adults and 52 children treated with the preparation over a period of 2 years, a distinct improvement in serological parameters and/or in blood parameters was found [34].

\section{Dosage and Treatment Duration}

The dosage and duration of the treatment with Padma 28 varied considerably, e.g., in $\mathrm{RC}$, the duration ranges from days to years. In the cardiovascular indications, the treatment duration was generally 16 weeks; in immunological indications, it was mostly 4-6 weeks. In the majority of the adult patients, the dosage was $2-3 \times 2$ tablets/capsules daily, in children it was $3 \times 1$, and in children of $<3$ years it was $3 \times 1 / 2$ tablet daily.

\section{Safety and Tolerability}

In 8 of the 29 studies there was no reporting on dropouts and AE. AE were relatively few $(n=39)$, and serious AE were rare $(n=9)$ and largely related to the underlying disease. Dropouts and withdrawals were about 2.5 times more frequent in the placebo than in the verum group. In the placebo group, the reasons for withdrawals were mainly worsening of the condition, failure to improve, and AE, while in the verum group they were poor compliance, insufficient efficacy, and AE. AE were about 3.5 times more frequent in the placebo than in the verum group. The most common $\mathrm{AE}$ in both groups were mild gastrointestinal symptoms, and in some cases, tiredness and skin conditions were reported. Nevertheless, the available results suggest a good safety and tolerability of Padma 28. 
Quality of the studies and level of evidence

The level of evidence according to the NHMRC (best I, lowest IV) was the highest in the indication of PAD Fontaine stage II. Most of the studies had a level II except 1 meta-analysis of level I [5], 1 cross over study of III-1 [8] and 1 open study of level IV [14]. The Jadad score (best 5, lowest 0) for methodical quality assessment is applicable only in randomized studies. Of the 8 studies in IC 1 had a Jadad score of 5, 2 scored 3 , another 2 scores 1 and 3 scored 0 .

In other cardiovascular diseases and studies on lipid metabolism levels of evidence were mostly III-1 and -2 except 2 studies of level II with Jadad scores of 0 and $3[16,19]$ and 1 RCS of level IV [32]. 1 randomized trial in MS had an evidence level of II [28]; the other studies in inflammatory and autoimmune diseases were not randomized and had evidence levels of III-2 to IV. Low Jadad scores were mainly found in older studies and due to lacking data on the method of randomization, blinding, and dropouts and withdrawals. The quality of the studies reflects the state of research at the time they were conducted.

\section{Discussion}

The systematic review produced a relatively high number of clinical studies on Padma 28, with 1,330 verum patients (1,704 if RC are included) and 727 controls. The studies originate from a time span of over 30 years and encompass a broad field of indications. From a Western medical point of view, this is a very broad spectrum of applications. However, from the traditional context of Tibetan Medicine this reflects the actual use in practice. Here, the formula Gabur 25, on which Padma 28 is based, is used as a general anti-inflammatory treatment and in so-called 'hidden fever', which could be translated as chronic inflammatory disorders [35]. Moreover, this formula is specifically used in disturbed blood circulation, to support wound healing, and in inflammations of various origins, especially in respiratory tract infections.

In the Western context, the formula is mainly used in circulatory disorders. The focus of the clinical trials lies in atherosclerotic diseases such as PAD, which is a manifestation of generalized atherosclerotic disease [36]. The results of the studies in angina pectoris, ischemic stroke, and intellectual impairment due to atherosclerosis support the hypothesis that Padma 28 is not only effective in symptoms of atherosclerosis of the leg and pelvic arteries leading to intermittent claudication. With its broad spectrum of systemic anti-inflammatory effects, it might also be effective in other atherosclerotic diseases. The herbal formula seems to act according to a multitarget mode of action, on the basis of which different pathogenic pathways are modulated at the same time [1, 2, 37]. Among other mechanisms, anti-hyperlipidemic and antioxidative activities seem to play a role $[1,19,20,38]$. Further factors contributing to its anti-atherosclerotic effects are various anti-inflammatory and immunomodulatory activities $[1,13$, 16, 21-23]. Inflammation is not only a contributor to atherogenesis but also seems to be a common denominator between different chronic inflammatory diseases, and obviously plays a role in autoimmune diseases.
This may partly explain why Padma 28 has also shown some efficacy in different inflammatory diseases. Many studies in these indications were done in Poland [39]. They generally date back before the implementation of International Conference on Harmonization (ICH) guidelines and are thus of a quite lower quality than today's standards and, except for the study in multiple sclerosis [28], were not placebo-controlled. In Poland, the preparation has been used since decades also in pediatric patients. This is reflected by the fact that most clinical data were found in only 1 indication in children. Of the 1704 patients treated with Padma 28 in the clinical studies and RCSs, 697 (41\%) were children, and the indication in 633 (37\% of the patients) was recurrent respiratory lower tract infections. However, in other countries, e.g. in Switzerland, there are no dosages for children given in the package insert because the indication is limited to symptoms of impaired circulation, which usually appear only in adults.

Studies in other inflammatory indications such as in dental pulpitis, viral hepatitis, or multiple sclerosis indicate a possible therapeutic value of the formula in these fields, and the results would merit further investigation in RCT. Nevertheless, the RCS of Bommeli et al. [32] showed that Padma 28 may be used in indications besides its registered use of circulatory disorders by medical practitioners, mainly as a supportive treatment in cardiovascular disorders and chronic inflammatory conditions. Because of its favorable safety profile and high tolerability, such a use seems justified, especially in chronic conditions where a 'gold standard treatment' is missing.

Regarding the possibility of drug interactions, none have been reported in the 3 decades of use in Western countries. Nevertheless, CT are urgently needed to obtain reliable data.

\section{Conclusions}

The formula Padma 28 has been established in Europe for 35 years, not only in the treatment of patients but also in experimental and clinical research. The body of evidence shows efficacy of the formula in atherosclerosis and supports its use in cardiovascular disorders as well as in some inflammatory conditions. A meta-analysis, as the highest level of evidence, is available for the treatment of PAD. Other studies show also some efficacy in chronic inflammatory conditions and suggest possible positive effects, e.g. in chronic recurrent infections in children, chronic active hepatitis $\mathrm{B}$, and multiple sclerosis. The studies included 1,704 verum-treated patients, $41 \%$ of them children, and show the formula to have a favorable safety profile. In summary, Padma 28 offers a safe and effective symptomatic treatment option in PAD. In view of its good tolerability in other forms of atherosclerosis and chronic inflammatory diseases, the study findings give a kind of rationale for its use in other clinical conditions, although further studies are urgently needed to confirm these data.

\section{Disclosure Statement}

C.V. is an employee of Padma Inc. Otherwise the authors declare no conflict of interest. 


\section{References}

1 Ueberall F, Fuchs D, Vennos C: Das anti-inflammatorische Potential von Padma 28 - Übersicht experimenteller Daten zur antiatherogenen Wirkung und Diskussion des Vielstoffkonzepts. Forsch Komplementmed 2006;13(suppl 1):7-12.

2 Schwabl H, Vennos C, Saller R: Tibetische Rezepturen als pleiotrope Signaturen - Einsatz von Netzwerk-Arzneien bei Multimorbidität. Forsch Komplementmed 2013;(suppl 2):35-40.

$\checkmark 3$ Jadad AR, Moore RA, Carroll D, et al.: Assessing the quality of reports of randomized clinical trials: is blinding necessary? Control Clin Trials 1996;17: 1-12.

4 National Health and Medical Research Council (NHMRC): A Guide to the Development, Implementation and Evaluation of Clinical Practice Guidelines, Appendix B. Commonwealth of Australia, 1999, p 56.

5 Melzer J, Brignoli R, Diehm C, Reichling J, Do DD, Saller R: Treating intermittent claudication with Tibetan medicine Padma 28: does it work? Atherosclerosis 2006;189:39-46.

6 Drabaek H, Mehlsen J, Himmelstrup H, Winther $\mathrm{K}$ : A botanical compound, Padma 28, increases walking distance in stable intermittent claudication. Angiology 1993;44:863-867.

7 Sommoggy S, Schleicher P: Therapie der peripheren arteriellen Verschlusskrankheit (PAVK) mit Padma 28. Studie I - Klinische und immunologische Wirkung von Padma 28 beim Patienten mit PAVK im Stadium II nach Fontaine. Unpublished final report supplied by the Department of Vascular Surgery, Technical University Munich and Zytognost GmbH, Munich; June 26, 1990.

8 Samochowiec L, Wojcicki J, Kosmider K, Dadej R, Smulski H: Wirksamkeitsprüfung von PADMA 28 bei der Behandlung von Patienten mit chronischen arteriellen Durchblutungsstörungen, Teil 2. Polbiopharm Rep 1987;22:3-15.

9 Samochowiec L, Wojcicki J, Kosmider K, Dadej R, Smulski H: Wirksamkeitsprüfung von Padma 28 bei der Behandlung von Patienten mit chronischen arteriellen Durchblutungsstörungen (Claudicatio intermittens, Stadium II nach Fontaine). Herba Polonica 1987;33:29-41.

10 Schrader R, Nachbur B, Mahler F: Effects of the Tibetan herbal preparation Padma 28 in intermittent claudication. Schweiz Med Wochenschr 1985; 115:752-756.

11 Sallon S, Beer G, Rosenfeld J, Anner H, Volcoff D, Ginsberg G, et al.: The efficacy of Padma 28, a herbal preparation, in the treatment of intermittent claudication: a controlled double-blind pilot study with objective assessment of chronic occlusive arterial disease patients. J Vasc Invest 1998;4:129-136.

12 Smulski HS, Wojcicki J: Placebo-controlled, doubleblind trial to determine the efficacy of the Tibetan plant preparation Padma 28 for intermittent claudication. Altern Ther Health Med 1995;1:44-49.
3 Winther K, Kharazmi A, Himmelstrup H, Drabaek H, Mehlsen J: PADMA-28, a botanical compound decreases the oxidative burst response of monocytes and improves fibrinolysis in patients with stable intermittent claudication. Fibrinolysis 1994; 8(suppl 2):47-49.

14 Hürlimann F: Eine lamaistische Rezeptformel zur Behandlung der peripheren arteriellen Verschlusskrankheit. Schweiz Rundsch Med Prax 1978;67: 1407-1409.

15 Panjwani HK, Brzosko WJ: Influence of selected immunocorrecting drugs on intellectual function of the brain due to arteriosclerosis. Nowiny Lekarskie (Medical News) 1998;5:665-670.

16 Split W, Szydlowska M, Brzosko WJ: The estimation of the action of Padma-28 in the treatment of ischaemic brain stroke. Eur J Neurol 1998;5(suppl 1):9.

17 Wojcicki J, Samochowiec L, Dolata C: Treatment of angina pectoris with Padma 28. Polbiopharm Rep 1983;20:35-41.

18 Wojcicki J, Samochowiec L: Controlled doubleblind study of PADMA 28 in angina pectoris. Herba Polonica 1986;27:107-114.

19 Brunner-La Rocca HP, Schindler R, Schlumpf M, Saller R, Suter M: Effect of the Tibetan herbal preparation PADMA 28 on blood lipids and lipid oxidisability in subjects with mild hypercholesterinaemia. VASA 2005;34:11-17.

20 Samochowiec J, Palacz A, Bobins W, Lisiecka B: Oscillating potentials of electroretinogram in the evaluation of the effects of Padma 28 on lipid metabolism and vascular changes in human. Phytother Res 1992;6:200-204.

21 Jankowski A, Jankowska R, Brzosko WJ: Behandlung infektanfälliger Kinder mit Padma 28. Schweiz Z Ganzheitsmed 1992;4(suppl 1):22-23.

22 Jankowski S, Jankowski A, Zielinska S, Walczuk M, Brzosko WJ: Influence of Padma 28 on the spontaneous bactericidal activity of blood serum in children suffering from recurrent infections of the respiratory tract. Phytother Res 1991;5:120-123.

23 Jankowski A, Drabbik E, Szyszko Z, Stasiewicsz W, Brzosko WJ: Treatment with Padma 28 of children with recurrent infections of the respiratory tract. Therapiewoche Schweiz 1986;2:25-32.

24 Mansfeld HJ: Beeinflussung rezidivierender Atemwegsinfekte bei Kindern durch Immunostimulation. Therapeutikon 1988;2:707-712.

25 Prusek W, Jankowski A, Radomska G, Wieczorek E, Podowysocka M: Immunostimulation in recurrent respiratory tract infections therapy in children. Arch Immunol Ther Exp (Warsz) 1987;35:289-302.

26 Gladysz A, Juszczyk J, Brzosko WJ: Influence of Padma 28 on patients with chronic active hepatitis B. Phytother Res 1993;7:244-247.

27 Brzosko WJ, Badmajew W, Plachcinska J, Dabrowski M, Dabrowska B, Loch T: PADMA 28, a new drug for patients with HBsAg positive or negative chronic aggressive hepatitis. Hepatol Rapid Lit Rev 1982;8:Memo-H-1971.
8 Korwin-Piotrowska T, Nocon D, StankowskaChomicz A, Starkiewicz A, Wojcicki J, Samochowiec L: Experience of Padma 28 in multiple sclerosis. Phytother Res 1992;6:133-136.

29 Hasik J, Klinkiewicz H, Linke K, Stachowiak C, Korynkiewicz M, Brzosko WJ: Effectiveness of duodenal ulcer disease treatment by PADMA 28. Nowiny Lekarskie (Medical News) 1992;2:40-44.

30 Schleicher P: Wirkung von Padma 28 auf das Immunsystem bei Patienten mit Aquired Immunodeficiency Syndrom im Stadium des Pre-AIDS. Schweiz Z Ganzheitsmed 1990;2:58-62.

31 Brzosko WJ, Jankowski A, Prusek W, Ollendiek $\mathrm{H}$ : Influence of Padma 28 and the thymus extract on clinical and laboratory parameters of children with juvenile chronic arthritis. J Immunother 1991; 7:143-147.

32 Bommeli C, Bohnsack R, Kolb C: Praxiserfahrung mit einem Vielstoffpräparat aus der tibetischen Heilkunde. Retrospektive Fallstudie mit 147 Erfahrungsberichten. Erfahrungsheilkunde 2001;11:745-756.

33 Füllemann F: Padma 28 in the treatment of chronic dental pulpitis: an observational case study in 49 patients. Forsch Komplementmed 2006;13(suppl 1): 28-30.

34 Brzosko WJ, Jankowski A: PADMA 28 bei chronischer Hepatitis B: Klinische und immunologische Wirkungen. Schweiz Z Ganzheitsmed 1992;4(suppl 1):13-14.

35 Tsarong TJ: Handbook of Traditional Tibetan Drugs. Kalimpong, Tibetan Medical Publications, 1986.

36 Hirsch AT, Haskal ZJ, Hertzer NR, et al.: ACC/ AHA 2005 guidelines for the management of patients with peripheral arterial disease (lower extremity, renal, mesenteric, and abdominal aortic): executive summary of a collaborative report from the American Association for Vascular Surgery/ Society for Vascular Surgery, Society for Cardiovascular Angiography and Interventions, Society for Vascular Medicine and Biology, Society of Interventional Radiology, and the ACC/AHA Task Force on Practice Guidelines (Writing Committee to Develop Guidelines for the Management of $\mathrm{Pa}$ tients with Peripheral Arterial Disease). J Am Coll Cardiol 2006;47:1239-1312.

37 Klein A, Wrulich OA, Jenny M, Gruber P, Becker K, Fuchs D, Gostner JM, Überall F: Pathway-focused bioassays and transcriptone analysis contribute to a better activity monitoring of complex herbal remedies. BMC Genomics 2013;14:133.

38 Suter M, Richter C: Anti- and pro-oxidative properties of PADMA 28, a Tibetan herbal formula. Redox Rep 2000;5:17-22.

39 Röösli MB: Systematische Übersichtsarbeit: Klinische Studien zur Wirksamkeit und Sicherheit des phytotherapeutischen Kombinationspräparats PADMA 28. Dissertation an der Fakultät für Medizin, Universität Zürich, 2009. 